\title{
Espaços participativos nas políticas culturais brasileiras: encontros presenciais e o lugar do artístico e do cultura/na atuação política da sociedade civil
}

Lorena Avellar de Muniagurria ${ }^{1}$

\section{Resumo}

A partir de uma etnografia da atuação de representantes da sociedade civil nos principais espaços participativos institucionalizados do Ministério de Cultura brasileiro, discuto a importância de elementos comumente pensados como alheios à política institucional para a constituição destes representantes, dos seus grupos e redes de militância e de suas agendas políticas. Veremos que é a partir do compartilhamento de cantos, danças, festas e experiências consideradas pessoais e afetivas, entremeadas às discussões políticas, que essas pessoas se instituem como representantes legítimos de seus segmentos e se reconhecem como aliados nas políticas culturais, criando assim o próprio segmento que, para ser politicamente útil, primeiro precisa ser culturalmente significativo.

Palavras-chave: políticas culturais; conselhos participativos; culturas populares

${ }^{1}$ Programa de Pós-Graduação em Antropologia Social - USP/SP. Doutoranda em Antropologia Social. E-mail: loreavellar@gmail.com 


\section{Participatory spaces and cultural policies in Brazil: presencial meetings and the role of the artistic and the culture for the civil society political action}

\section{Abstract}

From an ethnography of civil society's representatives in the main participatory spaces of the Brazilian Ministry of Culture, I discuss the importance of elements commonly taken as strange to institutional politics for the construction of such representatives' legitimacy, of their militancy networks and of their political agendas. It is by sharing songs, dances, parties and political discussions - all of this experienced as something personal and affective - that these people are able to recognize themselves as allies in cultural policies. In this process, the cultural category itself is created. We will see how, in order to be politically useful, it first need to be culturally significant.

Keywords: cultural policies; participatory councils; popular culture

Desde 2011, no âmbito de uma pesquisa maior sobre políticas culturais no Brasil, acompanho representantes da "sociedade civil” em suas atuações no Conselho Nacional de Políticas Culturais/CNPC e seus atuais 17 colegiados setoriais. ${ }^{2}$ Trata-se de espaços participativos institucionais de abrangência nacional vinculados ao Ministério da Cultura/MinC que reúnem "representantes do governo" e "representantes da sociedade civil"

\footnotetext{
${ }^{2}$ A referida pesquisa corresponde a meu projeto de doutorado, intitulado "Políticas culturais e espaços participativos no Brasil contemporâneo: um estudo sobre as categorias cultura e política", conduzido no PPGAS/USP sob orientação da Pfra. Dra. Fernanda Peixoto. A pesquisa conta com o apoio da FAPESP.
} 
de várias regiões do país e de segmentos culturais para discutir as políticas públicas para a cultura. Seguindo essas pessoas nos trânsitos que realizam desde suas localidades e grupos de origem até as reuniões organizadas pelo Ministério, foi possível perceber que, junto com elas, também circulam lógicas, práticas, linguagens e gestos distintos, em movimentos que tanto se apoiam em relações preexistentes como criam novas relações, e que tanto borram as fronteiras do Estado quanto as instituem. Através desses trânsitos, diversos elementos próprios aos universos artísticos e culturais representados (como cantos, danças, rezas, festas, metáforas sofre o fotografar, sobre a prática curatorial, etc.) se fazem presentes nas reuniões oficiais do CNPC e nas de seus colegiados. Neste artigo, focando especialmente na área das "culturas populares" que, desde 2010, conta com um Colegiado Setorial junto ao CNPC, proponho discutir a importância dessa série de elementos comumente pensados como alheios à política institucional para os processos observados. Sugiro que elementos identificados como "artísticos" ou "culturais", na verdade, integram a linguagem e a prática "política" ali exercida, pois são centrais na constituição das legitimidades dos representantes da sociedade civil, assim como na construção dos seus grupos e redes de militância e de suas agendas políticas. ${ }^{3}$

Inicialmente, apresento brevemente o contexto da recente criação e proliferação de espaços participativos institucionais na cultura, e algumas das implicações deste processo para as redes de militância da área. Veremos como o reconhecimento oficial de um conjunto definido e limitado de segmentos, institucionalizados enquanto "colegiados setoriais", implica o rearranjo de categorias preexistentes, tanto em nível conceitual (por exemplo, o que são as "culturas populares"?) quanto em termos de relações e alianças concretas (quais manifestações culturais têm apresentado "representantes" para esse colegiado setorial e quais

\footnotetext{
${ }^{3}$ Reservo o uso do itálico para assinalar categorias êmicas ou nativas. 0 uso das aspas é dedicado à indicação de citações literais.
} 
têm se reconhecido enquanto pares no processo de construção de demandas conjuntas para este setor?).

Na sequência, a partir da análise de um evento específico, o Encontro Nacional das Culturas Populares e Tradicionais, realizado em 2013 (doravante Encontro), pretendo evidenciar como a construção da categoria "culturas populares" é um processo ainda em curso, que implica em uma relação dinâmica e de retroalimentação entre categorias já institucionalizadas e práticas concretas que tensionam seus limites. 0 Encontro é um exemplo especialmente interessante, pois ele permite perceber a centralidade que elementos artísticos e culturais possuem nesse processo, e como eles terminam por constituir o que é reconhecido por muitos como uma maneira específica de fazer política, que seria própria à cultura ou às culturas populares e distinta da maneira que o governo tem de fazer política. Veremos como, na verdade, existe uma reivindicação explícita de que o Estado reconheça essas outras maneiras de se fazer política, de modo que as lógicas e práticas próprias aos grupos da "sociedade civil" representados nos espaços participativos possam legitimamente se fazer presentes nas "reuniões com o governo".

Finalmente, teço algumas considerações sobre a necessidade de se aprofundar as reflexões acerca das práticas políticas contemporâneas no Brasil. Se as ideias de que o Estado não é um bloco monolítico e que políticas públicas não podem ser reduzidas a políticas estatais estão já bastante consolidadas, ainda parece ser necessário avançar na descrição de processos e categorias específicas, como é o caso de "participação", "democracia" e "cidadania”.

\section{Surgimento de espaços participativos institucionais e redef inições dos segmentos na área da cultura}

Os espaços participativos pesquisados surgiram na última década, no contexto de uma importante reestruturação do Ministério da Cultura realizada a partir da eleição de Luiz Inácio Lula da 
Silva para a presidência da República e da nomeação de Gilberto Gil para a pasta da Cultura. Diferente dos casos exemplares das áreas da Saúde, da Criança e do adolescente e da Assistência social (que constituíram suas primeiras experiências em espaços participativos pouco após a promulgação da Constituição Federal de 1988), na Cultura, a criação de conselhos gestores e a realização de conferências com ampla participação da sociedade civil é recente, datando de 2005. Nos níveis estaduais e municipais, as experiências são diversas, mas, de modo geral, a proliferação de conselhos e de conferências municipais e estaduais seguiu-se à reestruturação do MinC nos governos Lula (Calabre, 2010; Muniagurria, 2013; Rubim, 2010). ${ }^{4}$

As gestões dos ministros Gilberto Gil (2003-2006) e Juca Ferreira (2007-2010) têm sido tratadas como marcos na história das políticas culturais no Brasil. Entre meus informantes, elas são apontadas unanimemente como as melhores já existentes em nível federal, e como sendo responsáveis pela delineação de um novo entendimento de política pública para o setor cultural - o que, no entanto, não exclui a existência de críticas. Conforme apontei em trabalho anterior (Muniagurria, 2013), também entre pesquisadores há um aparente consenso de que nesses ministérios, especialmente no de Gil, houve uma mudança significativa na área das políticas culturais brasileiras. Autores como Barbalho (2007), Calabre (2007 e 2009) e Rubim (2006 e 2007) destacam, especialmente: a adoção de um conceito de "cultura" mais amplo, com uma passagem do foco da cultura erudita e de elite para manifestações mais variadas; a valorização da diversidade; a proposição de cultura como direito e cidadania; o surgimento de espaços participativos; e os esforços de institucionalização de um sistema nacional de políticas culturais. Contudo,

\footnotetext{
${ }^{4}$ Há registro de conselhos e de conferências na área cultural desde o período da ditadura civil-militar. Contudo, eles eram distintos dos atuais espaços participativos: eram integrados por poucos, em geral "notáveis" escolhidos diretamente pelo chefe do executivo, sem, portanto, contarem com participação popular (Calabre, 2010; Conh, 1984; Gohn, 2001; Miceli, 1984; Rubim, 2010; Tatagiba, 2010).
} 
eles não chegam a referendar a afirmação bastante frequente de que essas gestões teriam implicado em uma "ruptura" na história das políticas culturais brasileiras, ou de que corresponderiam à "primeira experiência efetiva" de política pública nacional para a cultura no nível federal. ${ }^{5}$

Nos discursos oficiais do MinC, três principais características são atribuídas à referida reestruturação. Primeiro, há a afirmação de que as mudanças corresponderam à construção de uma "verdadeira política cultural", uma "política de Estado": não mais ações isoladas e, sim, um conjunto de ações elaboradas e implementadas de maneira articulada e sistemática. Segundo, de que toda essa reestruturação se baseou em uma redefinição e ampliação da noção da cultura: para além do sentido restrito e tradicional que associa o termo às belas artes e à cultura erudita, "cultura" teria passado a ser concebida como tendo três dimensões básicas (cidadã, econômica e simbólica), sendo associada à diversidade e a uma "abordagem antropológica abrangente". Finalmente, de que todo esse processo foi feito com intensa participação da sociedade civil (MinC, 2007; 2012). Para a discussão aqui em questão, a ampliação do conceito de cultura e do diálogo com a sociedade civil é especialmente importante. De fato, foi possível observar uma proliferação de espaços participativos vinculados à estrutura oficial do MinC e de governos municipais e estaduais. No nível federal, os principais espaços participativos hoje existentes na área são as Conferências Nacionais, o Conselho Nacional de Políticas Culturais e seus Colegiados Setoriais - mas

\footnotetext{
${ }^{5}$ De fato, a cautela frente a esse tipo de afirmação é necessária. De toda a bibliografia consultada, alguns trabalhos são especialmente importantes para colocarmos em perspectiva a experiência petista no MinC, assim como seu discurso sobre inovação. Em especial, as investigações de Lia Calabre (2009), de Isaura Botelho (2001) e de Sérgio Miceli (1984) nos mostram que o Estado Novo e a ditadura civil-militar, apesar de terem sido experiências autoritárias, corresponderam a importantes momentos de criação de um sistema de cultura em nível nacional. Mostram também que, nesses períodos, existiram ações e programas muito diversos e que, mesmo em contextos de repressão, houve experiências que podem ser consideradas progressistas.
} 
também é comum serem realizados fóruns, grupos de trabalho, consultas públicas, seminários e outros tipos de reuniões. ${ }^{6}$

O CNPC, principal instância permanente de participação, é um órgão colegiado integrante da estrutura básica do MinC, e existe na sua configuração e funções atuais desde 2005. Ele tem por finalidade "propor a formulação de políticas públicas, com vistas a promover a articulação e o debate dos diferentes níveis de governo e a sociedade civil organizada, para o desenvolvimento e o fomento das atividades culturais no território nacional" (Decreto Federal 5.520/2005). Ao todo, possui 58 cadeiras, distribuídas entre catorze categorias distintas. A lista que especifica os integrantes é longa e bastante detalhada, e julguei desnecessário transcrevê-la aqui. Contudo, não deixaria de ser um exercício interessante, pois poderíamos verificar como uma série de catorze categorias distintas, que enumeram as 58 cadeiras, termina por ser percebida como uma divisão entre, basicamente, duas categorias: "governo" e "sociedade civil". Os Colegiados Setoriais, por sua vez, são órgãos consultivos ligados ao CNPC, com a atribuição de fornecer subsídios para a definição de políticas, diretrizes e estratégias dos respectivos "setores culturais". Diferentemente do CNPC, os colegiados possuem uma ampla maioria de sociedade civil, sendo constituídos, cada qual, por quinze representantes desta e por um número reduzido de representantes do governo, que varia conforme cada colegiado (dos que

\footnotetext{
${ }^{6} \mathrm{O}$ investimento na participação social e na chamada democracia participativa foi uma característica das gestões Lula em geral, e não uma exclusividade da área cultural. $\mathrm{Na}$ verdade, a participação social foi pensada como uma política pública, em si mesma tome-se como evidência disto a proposta de construção de uma Política Nacional de Participação Social (PNPS), instituída a partir da promulgação do Decreto presidencial no 8.243, de 23 de maio de 2014, que foi alvo de grande debate. As conferências nacionais também podem ser tomadas como outro indicador, uma vez que são consideras elemento fundamental na democracia participativa. Entre 2003 e 2012, em dez anos de administrações petistas no nível federal, ocorreram 87 conferências nacionais, enquanto entre 1941 (ano em que teria sido realizada a primeira conferência no Brasil) e 2002, foram apenas 41 (IPEA, 2012). Para os anos de 2013 e 2014, a previsão era de que fossem realizadas mais 19 conferências nacionais (Brasil, 2013).
} 
pude observar, entre três e quatro pessoas). Cada um dos Colegiados possui um assento no CNPC, que é contabilizado como sociedade civil.

As Setoriais surgiram em 2005 e, desde então, foram ampliadas tanto em número quanto em natureza das áreas representadas. Considero que este processo de criação e de multiplicação de fóruns setoriais é uma importante tradução institucional, dentre outras existentes, da ampliação da noção de "cultura utilizada" pelo MinC. Quando elas surgem, em 2005, sob a denominação de "câmaras setoriais", eram apenas cinco, correspondiam todas a áreas consideradas "artísticas", e foram vinculadas à Fundação Nacional e Artes/Funarte. Elas eram: Artes Visuais; Dança; Literatura, Livro e Leitura; Música; Teatro.7 Em 2007, após um período de inoperância, esses fóruns foram reinstituídos, passando a ser tratados pela denominação de "colegiados setoriais" e sendo vinculados não mais à Funarte, mas, sim, diretamente ao gabinete do Ministro. Essa transferência da Funarte para o Ministério deveu-se, em grande medida, ao entendimento de que era necessário ampliar os fóruns setoriais para além das linguagens artísticas. Assim, entre 2007 e 2010, foram constituídos grupos de trabalho responsáveis por pensar e propor novas setoriais. Em 2010, durante as Pré-Conferências Setoriais da II Conferência Nacional de Cultura, foram realizados os processos eleitorais que elegeram o novo mandato dos cinco colegiados já existentes e o primeiro das quatro novas setoriais - dentre elas, a do Colegiado Setorial de Culturas Populares/CSCP, caso que será aprofundado neste artigo. Em 2012, novamente durante o processo eleitoral de renovação dos colegiados, aconteceu uma nova ampliação, totalizando as dezessete setoriais hoje existentes: Arquitetura e Urbanismo; Arquivos; Arte Digital; Artes Visuais; Artesanato; Circo; Cultura dos Povos Indígenas; Culturas

\footnotetext{
${ }^{7}$ A Funarte é o órgão responsável, no âmbito federal, pelas políticas públicas para as Artes visuais, Música, Teatro, Dança e Circo. 0 órgão responsável pela política para a área de Livro, literatura e leitura é a Fundação Biblioteca Nacional/FBN.
} 
Afro-brasileiras; Culturas Populares; Dança; Design; Livro, Leitura e Literatura; Moda; Música; Patrimônio Imaterial; Patrimônio Material; Teatro.

Apesar de não ser possível aqui apresentar uma descrição detalhada das negociações que estiveram na base da criação do Colegiado Setorial de Culturas Populares, é importante mencionar que elas implicaram em uma série de disputas em torno do conceito e da nomenclatura a ser utilizada: seria uma setorial para o "folclore"? Qual a ideia de "popular" a ser utilizada? Ele poderia incluir manifestações urbanas como o hip hop? Um determinado entendimento de "cultura popular" começou a ser ali configurado. Contudo, a construção dessa categoria é um processo ainda em curso, no qual as negociações e renegociações em torno de seu significado e abrangência passam não apenas pelas definições institucionais já existentes, mas, também, por uma série de disputas e alianças entre pessoas, grupos e redes culturais que se querem "culturas populares".

Nestes anos de trabalho de campo, tenho observado que o CNPC e os colegiados setoriais são centrais nesse processo, pois eles têm mostrado ser importantes espaços de articulação das redes da sociedade civil. De modo geral, a partir do encontro e do convívio nesses fóruns nacionais, essas redes têm sido ampliadas e modificadas, e novos vínculos, redes e alianças têm surgido, em um processo que tem envolvido a (re)negociação e (re)construção de alguns sentidos e categorias. É fundamental perceber que, quando alguém participa pela primeira vez desses processos e espaços institucionalizados, ele ou ela adentra um lugar que já possui certas categorias estabelecidas (por exemplo, a divisão em determinados colegiados setoriais) e que não correspondem necessariamente à taxionomia previamente utilizada por estes sujeitos. A questão aqui é indagar-se sobre o que significa a existência de uma área concebida e designada como "colegiado setorial”. Quais as implicações da institucionalização de algo como objeto legítimo das políticas culturais? E da existência de um nú- 
mero delimitado de colegiados - quer dizer, da institucionalização de um número restrito de categorias de manifestações culturais? Hoje, toda e qualquer manifestação, prática ou processo que queira ser reconhecida como "cultura" e que queira se fazer presente nesses espaços participativos para demandar o apoio e a atenção do Estado brasileiro, deve conseguir se filiar, ou ao menos se aproximar, a um dos dezessete colegiados existentes ou lutar pela institucionalização de uma nova área. ${ }^{8}$

A existência de um número limitado de colegiados implica, portanto, uma série de processos de mediação que permitam a redução da virtualmente infinita diversidade da "cultura brasileira" às categorias institucionalizadas ou em vias de institucionalização. Essa redução é feita tanto através de exclusões quanto de novas sínteses, o que coloca problemas político-classificatórios delicados. As "culturas populares", portanto, assim como as outras setoriais do CNPC, são uma contínua reinvenção que articulam uma miríade de grupos e sujeitos muito distintos em sínteses que precisam harmonizar e aproximar manifestações tão diversas como o carimbó do Pará, o jongo do sudeste, o hip hop das periferias brasileiras ou as danças germânicas e o talian presentes no Sul do Brasil, para citar apenas alguns exemplos. A dificuldade colocada na construção dessas alianças deve-se ao fato de que, para que elas possam funcionar politicamente, é necessário antes que elas sejam culturalmente significativas: é preciso que faça sentido, do ponto de vista "cultural", associar o carimbó, a capoeira, as festas populares, as danças alemãs, o talian, o hip hop, etc. Sem isso, torna-se impossível articular demandas particulares a cada uma dessas diversas manifestações em torno de uma agenda política comum a todo o setor. Ou seja, o próprio "segmento" ou "setor" precisa ser construído enquanto categoria cultural e politicamente válida e legítima. Mas como, em que instâncias e de quais maneiras isso ocorre?

${ }^{8}$ Atualmente, algumas das áreas que reivindicam a criação de novos colegiados junto ao Ministério da Cultura são: Museus; Audiovisual e Cultura alimentar. 
Os encontros presenciais parecem ser especialmente importantes para esses processos de construção de alianças e, portanto, das categorias grupais. Na verdade, há uma grande reivindicação, especialmente por parte dos representantes da sociedade civil, por mais encontros presenciais. Como já foi mencionado, as reuniões do CNPC e dos colegiados têm mostrado ser importantes espaços para a articulação dos segmentos. Contudo, a solicitação mais frequente não é a de mais reuniões ordinárias dos Colegiados ou do CNPC, mas, sim, a da realização de mais eventos de grande porte, como os encontros setoriais regionais ou nacionais. Para se ter uma noção das dimensões, enquanto as reuniões do CNPC contam com quase 60 pessoas, e as dos colegiados com pouco mais de 15 participantes, os grandes encontros nacionais, como as Conferências Nacionais de Cultura, as Pré-conferências Setoriais, os Fóruns Setoriais ou as Teia da Diversidade, costumam receber entre 700 e 1500 pessoas. ${ }^{9}$ Além de envolverem muitas pessoas durante a etapa nacional, os grandes encontros também implicam etapas de mobilizações anteriores, nas esferas municipais e estaduais, em que são escolhidas as pessoas e propostas a serem enviadas à etapa nacional.

Mas o que parece tornar esses grandes encontros tão importantes não é apenas suas dimensões ampliadas ou a grande mobilização que eles requerem, e sim sua maior abertura para diversos tipos de atividades e trocas de experiências, que não são apenas aquelas consideradas típicas de uma reunião de governo. Os grandes encontros são vivenciados como uma experiência especialmente intensa. Um dos principais aspectos que

\footnotetext{
${ }^{9}$ Mesmo sendo pensadas como momentos excepcionais, esses grandes encontros não têm sido raridade. Atendo-nos apenas aos anos mais recentes: em 2012, foram realizados Fóruns Setoriais Nacionais, que elegeram os representantes dos colegiados para o mandato de 2012-2015; em 2013, ano da III Conferência Nacional de Cultura, como parte de seu processo, aconteceram diversos grandes encontros; em 2014, teve lugar a Teia Nacional da Diversidade Cultural (encontro nacional dos Pontos de Cultura); e está prevista a realização, no segundo semestre de 2015, da nova edição dos Fóruns Setoriais Nacionais, quando serão eleitos os integrantes para o novo mandato dos colegiados setoriais.
} 
faz esses encontros nacionais serem percebidos como intensos é o fato da convivência entre as pessoas ser enorme. Normalmente, a hospedagem acontece em poucos hotéis, frequentemente próximos um do outro e do local do evento, de modo que compartilha-se dos mais diversos momentos, do café da manhã aos grupos de trabalho, passando pelos momentos de socialização festiva nos intervalos. Tanto na programação oficial quanto de improviso, nunca faltam apresentações artísticas e culturais, e elas constituem sempre momentos especialmente prestigiados, valorizados e comentados durante os encontros. Há grupos de trabalho, há rodas de troca de experiências e de discussões políticas, e há também conversas de bar, de corredor, shows e festas. Há muito trabalho, e há também muita festa - conferências nacionais, por exemplo, são frequentemente descritas como grande festa da cidadania, ou grande festa da democracia.

Existe uma vasta bibliografia que analisa as festas como rituais e que destaca o poder que elas possuem para aproximar e vincular indivíduos. ${ }^{10}$ Aqui, mais do que pensar a festa como evento específico, interessa considerar o caráter festivo de certos modos de sociabilidade, que podem se fazer presentes em diversos tipos de eventos e ocasiões - inclusive, por exemplo, nos momentos de trabalho e de discussão política desses grandes encontros participativos. Esse tipo de reuniões pode então ser abordado com o auxílio da já longa tradição antropológica de análise de eventos rituais - penso aqui, em especial, em uma linhagem recuperada por Peirano (2001), que passa por autores como Leach (1995 [1954]); Turner (1974 [1969]; 1988) e Tambiah (1996). Tal qual outros grandes eventos rituais analisados para o caso da sociedade brasileira, como o carnaval e as eleições (Palmeira, 2001; Cavalcanti, 1995), esses encontros são capazes de configurar tempo e espaço de maneira diferenciada, distinta ao cotidiano. Na fala nativa, isso ganha concretude em formulações

${ }^{10}$ Para uma revisão bibliográfica sobre o tema, conferir Perez (2012) e Amaral (2001). 
como "ano de Conferência” ou "ano de Teia”. Esse novo território, que é o encontro ou a reunião, é marcado por uma intensa concentração, dada pela própria concentração física e temporal do evento, em que tudo - hospedagem, refeições, reuniões de trabalho, festas e atividades paralelas - costuma acontecer em poucos dias (em geral, entre dois e cinco) e em um mesmo local ou em locais justapostos. Viagens, hotéis, centros de convenção; refeições servidas para todas essas pessoas em grandes refeitórios; credenciamento, entrega de bolsas e materiais impressos para o trabalho no evento; discussões nos grupos de trabalho; festas e atividades culturais... e muitas rodas. Seja sentados em cadeiras em uma sala onde acontece um grupo de trabalho; seja em um canto improvisado, sentados no chão em um corredor, saguão ou área externa, sempre há círculos de pessoas. Rodas de conversas informais; rodas de GTs; rodas de capoeira; rodas de samba... Muitas rodas.

Normalmente, no último dia de um grande encontro, há uma assembleia ou plenária geral final. Quando chega esse momento, muito já foi vivido, muitas rodas aconteceram. Interessa aqui perceber a importância da convivência, da troca de experiências e do caráter festivo presente nesses grandes encontros. E, especialmente, realizar o papel que dançar, cantar, recitar, fotografar, e uma série de outras práticas e elementos próprios aos universos culturais ali representados, possuem nessa dinâmica e nessa "experiência intensa". Pois, como veremos no exemplo aprofundado a seguir, é a partir da articulação de "discussões políticas" com o compartilhamento de certas experiências "artísticas", "culturais" e "festivas", marcadas por elementos oriundos dos campos artísticos e culturais representados, que essas pessoas se instituem como representantes legítimos de seus segmentos e que elas se reconhecem como parceiros e aliados nas lutas que empreendem nas políticas culturais. Festas, rodas de música, conversas de bar, conversas de corredor, apresentações artísticas são, portanto, fundamentais, e possuem uma eficácia propriamente política. 


\section{Encontro nacional das culturas populares e tradicionais: encontros presenciais e o lugar do artístico e do cultural na política}

0 "Encontro Nacional das Culturas Populares e Tradicionais" foi realizado em São Paulo/SP, na sede do SESC Itaquera, entre os dias 1 e 6 de outubro de 2013. Tratou-se de uma iniciativa da Rede de Culturas Populares e Tradicionais/RCPT e do Fórum das Culturas Populares e Tradicionais/FCPT, ambos reconhecidos como importantes redes de militância da sociedade civil na área das culturas populares e tradicionais, e que participaram da própria criação do Colegiado Setorial de Culturas Populares e, atualmente, possuem associados em diversos dos colegiados setoriais existentes. ${ }^{11} \mathrm{O}$ Encontro foi um evento dedicado à discussão de políticas públicas para o segmento das "culturas populares e tradicionais" e, aproveitando 2013 ter sido ano de Conferência Nacional de Cultura/CNC, foi inscrito no processo de construção da III CNC como Conferência Livre. ${ }^{12}$ Devido a ter

${ }^{11}$ A RCPT é uma rede de articulação que conta com integrantes de diversos estados do país e que tem por principais meios de contato e de comunicação um grupo de e-mail e uma página no Facebook. Segundo depoimento de um de seus fundadores, ela existe desde meados de 2005, e propõe-se a ser uma estrutura de mobilização horizontal, sem uma direção centralizada. 0 Fórum, por sua vez, é uma associação institucionalizada, com CNPJ. Seu estatuto o define como uma associação nacional, mas iniciou-se a partir de um grupo de militantes paulistas e, até onde pude constatar, mesmo atualmente, a maior parte de seus integrantes reside ou atua principalmente no estado de São Paulo. Existe uma superposição entre a Rede e o Fórum: apesar de a primeira ser mais ampla tanto em número de integrantes quanto em abrangência nacional, em inúmeras ocasiões durante o campo, vi pessoas associando-a ao Fórum ou, inclusive, ignorando a existência de uma diferença entre ambos. Atualmente, o Fórum cumpre a função de "diretoria executiva" da Rede de Culturas Populares. A ideia de criar essa diretoria teria vindo da percepção de ser necessário um "braço" com maior grau de formalização, de modo a que a Rede pudesse acessar recursos via editais públicos e outros tipos de parcerias oficiais. ${ }^{12}$ Segundo o regulamento da III CNC, conferências livres poderiam ser promovidas e organizadas pelos mais variados âmbitos da sociedade civil e do poder público e seriam responsabilidade dos segmentos e entidades que as convocassem. Distintamente do processo coordenado pelo MinC, elas poderiam ser dedicadas a debater temáticas específicas. Ao todo, aconteceram 35 conferências livres em todo o país. Cada uma delas pôde enviar propostas e um delegado para a etapa nacional da III CNC. 
alcançado abrangência nacional, com a presença de representantes de vários estados e de todas as regiões do Brasil, ela foi considerada por muitos como equivalente a uma "pré-conferência setorial nacional" do segmento das culturas populares. Para se ter uma ideia das dimensões, o Encontro teve mais de 800 participantes e custou mais de dois milhões de reais. Tamanhos custos - referentes não apenas à produção do evento propriamente dito, mas também ao financiamento do transporte, hospedagem e alimentação da maior parte dos participantes - apenas puderam ser cobertos graças a uma série de parcerias com a iniciativa privada e com o poder público. ${ }^{13}$

O Encontro, portanto, é um exemplo de eventos que são possíveis apenas graças a um emaranhado institucional (Vianna, 2014), pois requereu diferentes tipos de aportes (financeiros, logísticos, de articulação e mobilização política) e o envolvimento de agentes e instituições localizados em distintas esferas da federação e com capilaridade ao longo do território brasileiro. Ele possui, ainda, todas as características do que estou chamando de "grandes encontros": reuniu um alto número de participantes, residentes em distintas cidades e regiões do Brasil; implicou, portanto, em uma série de deslocamentos, viagens majoritariamente aéreas, além da necessidade de hospedagem; sua realização demandou a parceria de várias instituições e redes; possuiu uma "agenda de trabalho", dedicada à discussão de políticas culturais, mas também uma intensa "agenda cultural", além de ocasiões de sociabilidade com forte caráter festivo.

\footnotetext{
${ }^{13}$ O principal parceiro do evento foi o SESC/SP, que forneceu local, infraestrutura, recursos humanos e recursos financeiros. 0 segundo principal parceiro foi o MinC, através da Secretaria da Cidadania e da Diversidade Cultural/SCDC, que contribuiu com recursos financeiros, humanos e certo apoio logístico, devido à realização de reuniões ordinárias de seis Colegiados Setoriais durante o Encontro. Outros parceiros foram: o mandato do Deputado Federal Vicente Cândido (PT/SP), a Secretaria Municipal de Cultura de São Paulo e a Secretaria Estadual de Cultura de São Paulo.
} 
Uma minuta da proposta para o Encontro, publicada no grupo de e-mails e no perfil de Facebook da Rede em julho de 2013, apresentava o evento da seguinte maneira:

0 Encontro reunirá detentores dos conhecimentos e expressões culturais populares e dos povos e comunidades tradicionais de todo o país, além de artistas, lideranças e gestores articulados em rede(s) e agentes escolhidos para funções de representação em diversas instâncias de pactuação entre o Estado e sociedade civil organizada. [...] 0 objetivo principal é o de vivenciar profundamente aspectos da diversidade cultural brasileira associados às expressões populares e tradicionais. É, também, construído para avaliar políticas públicas implantadas nos últimos 10 anos e propor diretrizes para um novo ciclo. As áreas de abrangência poderão compreender as Culturas Populares, Artesanato, Hip Hop, Culturas Indígenas, Circo, Teatro de Rua, Patrimônio Imaterial, Culturas Afro-brasileiras, Povos de Matriz Africana e outros Povos e Comunidades Tradicionais.

As atividades serão: exposições, rodas de conversa, grupos de trabalho, mostra da culinária e do artesanato tradicional, vivências e apresentações que tentarão recriar o ambiente das festas populares, momentos mais complexos e condensados de expressão dessa cultura. A dinâmica do encontro deverá ser inovadora no sentido de não reproduzir o padrão tradicional dos seminários institucionais ou acadêmicos, com a formação de mesas e plateias. Ela deve se possível, prever formas variadas e integradas de participação, em agrupamentos de dimensões distintas, que permitam a livre discussão dos temas propostos. Os momentos de convivência, refeições e da mostra artística serão tão importantes quanto as mesas para a produção dos conteúdos esperados. A mostra artística deve tentar reproduzir ao máximo a dinâmica própria das performances tradicionais e permitir a participação do público o tempo todo, sem a caracterização de espetáculo ou apresentação. (Grupo de e-mail da RCPT, correspondência de julho de 2013. Destaques da autora.)

Com algumas alterações e reduções, esse foi o texto assinado pelo Fórum no encarte impresso da programação do Encon- 
tro. ${ }^{14}$ Como pode ser visto, a metodologia e as dinâmicas de trabalho propostas pretendiam colocar em pé de igualdade, e entremear momentos que poderiam ser ditos como de "discussão política" com os de "convivência", assim como valorizar a "troca de experiências" e favorecer as dinâmicas tidas como próprias às "culturas populares". Como veremos adiante, essa preocupação encontrou tradução em diversos aspectos do Encontro. Na programação oficial, procurou-se intercalar e associar os momentos de discussão com os de apresentações culturais. Em relação a essa agenda cultural, chamou atenção que a grande maioria das pessoas que participou da mostra artística era também inscrita no Encontro como participante, o que significou ter critérios "culturais" organizando as delegações de representantes e, ao mesmo tempo, ter critérios "políticos" organizando as apresentações artísticas. Finalmente, em relação ao espaço físico, visando favorecer as dinâmicas consideradas próprias às culturas populares e tradicionais, a organização optou por manter grandes áreas livres para as apresentações e para a plenária; preferiu fazer as apresentações diretamente no chão ou, quando estritamente necessário, sobre palcos o mais baixo possível; escolheu montar tendas, e não salas, para as Rodas de Conversa; e contratou uma produtora de ambientação que investiu no multicolorido, no uso de retalhos de tecido, de fitas, bambus e bonecos. ${ }^{15}$

\footnotetext{
${ }^{14}$ Destacaria como alterações significativas: a exclusão da citação nominal do Hip Hop e do Circo; a eliminação ou suavização de trechos que comentam as dinâmicas de trabalho propostas para o evento, que se contrapunham ao "padrão tradicional dos seminários institucionais ou acadêmicos"; a inclusão da informação desse ser o sétimo encontro presencial dos membros da Rede; e a inclusão da informação de que o Encontro integraria o processo da III CNC como conferência livre.

${ }^{15}$ No site da Celophane, responsável pela criação e produção desses espaços e decorações, a ambientação é proposta como "um elemento que amarra e costura as culturas populares como uma enorme colcha de retalhos, emoldurada por bambus e adornada com flores de papel e fitas coloridas". Enquanto metáfora visual para as culturas populares, ela também foi entendida como "diversas pipas vindas de várias localidades do Brasil se encontrando, amarrando experiências, discutindo propostas em conjunto, cobrando as autoridades públicas o que é de direito." Algumas imagens da ambientação podem ser conferidas no site dessa empresa de produção: http://celophanecultural.com.br/cenografia/encontro-de-culturas-populares-e-tradicionais-sesc-itaquera
} 
Vejamos um pouco da estrutura desse encontro. A programação oficial final incluiu seis tipos de atividades: (i) reuniões de seis Colegiados Setoriais e da Comissão Nacional dos Pontos de Cultura/CNdPC; (ii) cinco Rodas de conversa e convivência; (iii) oficinas; (iv) programação cultural; (v) feira de artesanato; e (vi) mostras culinárias. Na prática, o Encontro teve dois principais momentos. 0 primeiro, nos dias 1 e 2 de outubro, antecedeu o encontro propriamente dito, e foi dedicado às reuniões dos colegiados setoriais e da CNdPC. A participação nessas reuniões restringiu-se aos conselheiros titulares, além da presença de alguns poucos suplentes e ouvintes. A ideia de realizar essas reuniões junto ao Encontro partiu dos organizadores do evento e visava viabilizar a presença desses representantes no evento. A proposta, que foi aceita pelo MinC, era a de que este transferisse, de Brasília para São Paulo, uma das reuniões ordinárias de seis colegiados que, segundo a organização do evento, compartilham da mesma base social que as culturas populares. Assim, sem que isso implicasse em um dispêndio extra, o gasto com as passagens, hospedagens e alimentação desses representantes seria pago pelo Ministério, criando-se ainda o benefício dessa ocasião de trocas e articulação "intersetorial". ${ }^{16}$

É apenas no dia 3 que o Encontro realmente começa, com a presença dos mais de 800 participantes inscritos. As principais atividades, a partir de então, foram as "Rodas de Conversa e de Convivência e a Programação cultural”. As rodas foram consideradas o principal espaço de discussão política do evento, e foram também a base para a produção das propostas votadas na plenária final do Encontro. Elas contaram com um público ampliado, bastante heterogêneo em relação às suas experiências pregressas de participação em espaços participativos. Livre da necessi-

\footnotetext{
${ }^{16}$ As setoriais convidadas foram: Artesanato, Circo, Culturas Afro-brasileiras, Culturas dos Povos Indígenas, Culturas Populares e Patrimônio Imaterial. Apenas o Colegiado de Circo não aceitou o convite. Em contrapartida, o Colegiado de Patrimônio Material pediu para participar do Encontro, argumentando que o entendimento contemporâneo do patrimônio material valoriza a articulação com as dimensões imateriais.
} 
dade de terem de seguir a separação setorial colocada para as reuniões dos colegiados, a organização pode propor outros critérios para as Rodas, permitindo focalizar discussões de maneira diferenciada do que acontece junto aos fóruns permanentes do MinC. A escolha por denominá-las "rodas de conversa e de convivência" (e não GTs ou Eixos, como normalmente acontece nos fóruns e conferências organizados pelo Ministério), correspondeu justamente ao esforço de demarcar a possibilidade de um tipo de espaço e de modo de organização das discussões distinto do "padrão tradicional dos seminários institucionais ou acadêmicos". ${ }^{17}$ Mas, o que de fato marcou a diferença foi a mostra artística. Apesar dos grandes encontros organizados pelo MinC normalmente incluírem uma agenda cultural (especialmente nos casos das Conferências Nacionais), a do Encontro foi bastante distinta. Considero duas diferenças como as mais significativas. Primeiro, o fato de essa programação ter sido extensa e não ter ocupado apenas o final do dia, mas sim vários momentos de cada data do Encontro, intercalando-se com os turnos dedicados às Rodas de Conversa e ocupando inclusive os horários de refeição. E segundo, talvez mais importante, o fato de que as pessoas que se apresentaram eram as mesmas que participavam das discussões políticas.

É fundamental perceber, nesse Encontro, que a importância atribuída aos modos e práticas identificados com as culturas populares não estava desvinculada da intenção de construir um encontro de discussão política: conforme pude ouvir de um dos organizadores, a finalidade do evento e das apresentações culturais não era "estética", mas sim "política". Como se dá, então, essa importância política de elementos que são reconhecidos por todos - participantes e organizadores - como "estéticos", "cul-

\footnotetext{
${ }^{17} \mathrm{O}$ nome das cinco rodas de conversa foram: (i) Conhecimentos tradicionais - Marcos Legais para Promoção e Proteção; (ii) Democratização dos Meios de Comunicação; (iii) Territórios Tradicionais; (iv) Relação do Estado com a Sociedade Civil; (v) Novas Tecnologias, Juventude e Culturas Tradicionais.
} 
turais" ou "artísticos"? Analisar como a coordenação do evento tratou da programação cultural pode iluminar alguns aspectos dessa questão. Segundo um dos produtores e organizadores (ativo militante no setor, integrante tanto do FCPT quanto da RCPT, como também do Colegiado Setorial de Culturas Afro-brasileiras), a escolha dos grupos que integraram a programação cultural oficial seguiu alguns critérios: cobrir o máximo de regiões e manifestações do Brasil; evitar grupos para-folclóricos ou de releituras; evitar "estrelismos", escolhendo grupos que não fizessem parte daqueles que costumam integrar as várias agendas de "apresentações espetacularizadas" de manifestações populares; e escolher grupos e pessoas que pudessem contribuir com as discussões acerca das políticas culturais para a área. Os participantes seriam, portanto, tanto os debatedores das questões políticas quanto os responsáveis pelas apresentações artísticas e culturais. Vemos, aqui, que tanto critérios políticos como estéticos pautaram a escolha dos grupos que se apresentariam - novamente, uma preocupação "política" e não apenas ou primordialmente "estética".18

As manifestações artísticas escolhidas foram: afoxé, viola caipira, teatro de mamulengo, jongo, tambor de crioula, chegança de marujos, folias, danças indígenas (dos Karajás/TO e dos Kala-

\footnotetext{
${ }^{18}$ Apesar de todos os cuidados, vários foram os momentos em que as apresentações se configuraram de maneira "espetacularizada": quer dizer, nos próprios termos propostos pela organização, com a configuração de uma "plateia", distinta e separada do grupo que se apresentava. Quando uma apresentação acontecia, impressionava a quantidade de pessoas que se aproximavam para filmar e fotografar: não raro, se a apresentação fosse no chão, o grupo ficava rodeado, completamente englobado por um conjunto de pessoas com celulares, máquinas de fotografar e de filmar. Contudo, há de se destacar que quem se apresentava não estava ali na posição de alguém que, após sua performance, recebia aplausos, agradecia e se retirava; todos estavam nos mesmos hotéis, compartilhavam das mesmas refeições, participavam das rodas de conversa e discussões, e eram também "público" dos outros grupos. Em relação a esse ponto, até onde pude verificar, houve duas exceções: o grupo de teatro de rua "Pombas Urbanas" e os músicos do show “Bá”. A programação pode ser conferida em: www.culturaspopulares.org.br/download/Release\%20-\%20Encontro. doc Além do pagamento dos custos com deslocamento, hospedagem e alimentação, as pessoas que entraram na programação oficial receberam também cachê pelo SESC/SP.
} 
palo/MT), cavalo marinho, bumba meu boi, congada, carimbó, fandango, samba de roda, maracatu rural e cortejo de rua. Um elemento bastante interessante na organização dessas apresentações foi que, em vários casos, ao invés de trazer um único grupo local - como foi, por exemplo, o caso do Boi do Seu Teodoro (DF) - optou-se por construir espécies de delegações de uma manifestação, integradas por representantes de grupos distintos, de cidades ou até estados diferentes, que faziam suas apresentações conjuntamente. Foi o caso do Jongo do Sudeste (com a presença de mestres de quatro estados: São Paulo, Rio de Janeiro, Minas Gerais e Espírito Santo); do Carimbó do Pará (com mestres de várias regiões deste estado); do Maracatu Rural e do Cavalo Marinho (ambos apresentados por mestres de folguedos da Zona da Mata Pernambucana); do Samba de Roda do Recôncavo Baiano (com representantes de mais de um grupo desta região); do Fandango Caiçara (com mestres do Paraná e de São Paulo); e das Folias de Roraima (também com mestres de mais de um grupo deste estado). A ideia era, com isso, conseguir garantir uma diversidade interna para cada uma dessas manifestações, e aumentar o alcance em relação às redes e grupos presentes no Encontro. Além disso, a seleção dessas pessoas foi feita a partir da indicação de contatos regionais dos organizadores, lançando mão das relações da Rede e do Fórum. Quer dizer que esses representantes foram selecionados através de uma rede que não é apenas de "culturas populares e tradicionais", mas, especificamente, uma rede preocupada com políticas públicas para este segmento.

Foram essas mesmas pessoas, então, que cantaram, tocaram e dançaram, as que participaram das Rodas de Conversas. Nessas rodas, vários tipos de debates e conversas aconteceram. Na que pude acompanhar, "Conhecimentos tradicionais" - "marcos legais para promoção e proteção", parte importante da conversa foi relatar experiências particulares de dificuldades enfrentadas pelos grupos ali representados: populações tradicionais na Amazônia que repentinamente, frente ao registro de uma paten- 
te, ou a uma nova legislação ambiental, perderam o direito de utilizar plantas das quais tradicionalmente fazem uso; populações caiçaras do litoral paranaense que foram desconsideradas quando da criação de Unidades de Conservação e que então, do dia pra noite, viraram "caso de polícia”, pois habitavam um lugar que passou a ter inúmeras restrições à presença de populações humanas; baianas vendedoras de acarajé em Salvador que, com a realização da Copa do Mundo no Brasil, em 2014, seriam proibidas de comercializar nas áreas próximas ao estádio (isto, mesmo sendo o acarajé registrado como patrimônio imaterial brasileiro e devendo, portanto, ser protegido e promovido pelo Estado). "Eu vim aqui pedir ajuda" - ouvi isto nesse encontro, assim como em outras reuniões que tive ocasião de etnografar. Como lidar com essas situações? Existem proteções legais que possam ser utilizadas ou elas ainda precisam ser criadas? Que atores, setores ou medidas legais uma comunidade como a caiçara, por exemplo, poderia acionar para proteger-se da violência policial, para garantir o direito à pesca artesanal, ou à retirada de alguns espécimes de árvores para poder continuar construindo suas rabecas? Se não em todos os casos, para muitos dos presentes, a possibilidade de manutenção de sua "cultura" significava a própria possibilidade de continuidade da comunidade. Assim, manifestações e grupos culturais bastante diversos encontraram necessidades e demandas em comum: garantir o acesso aos recursos naturais; produzir uma legislação para a proteção da propriedade intelectual coletiva; construir instâncias de diálogo transversais a distintos ministérios e setores do Estado, de modo a diminuir os problemas resultantes da existência de legislações e ações estatais conflituosas.

Esse evento, com suas discussões políticas e suas apresentações artísticas, possibilitou "conhecer" o trabalho do outro, as lutas do outro, e reconhecer-se como pares. Dançar junto, conhecer e comparar seus tambores, suas canções e suas crenças, suas histórias; ouvir os relatos e testemunhos sobre as dificuldades que cada grupo enfrenta para poder "manter viva sua tradição"; 
tentar construir propostas de diretrizes para o segmento como um todo... Tudo isso fez parte de um grande encontro de trocas de experiência. Os depoimentos são claros nesse sentido: reforçam sempre a possibilidade de sair da sua cidade (muitas vezes, de interior); conhecer o trabalho e as pessoas de cidades e regiões tão distantes; conhecer manifestações tão diferentes; e aprender a valorizá-las, pois estavam ali também querendo que os outros conhecessem, valorizassem e respeitassem as suas. É aqui que surge a eficácia do festivo e desses elementos artísticos e culturais.

Tenho trabalhado a ideia de eficácia a partir dos trabalhos de autores como Steven Feld (1982), Alfred Gell (1998; 2006) e Annelise Riles (2000), que adotam uma abordagem dita estética ou formal estreitamente ligada ao estudo das práticas. Isso significa procurar entender o poder que certas formas têm de afetar as pessoas ao seu redor - emocioná-las ou fazê-las chorar, no caso dos Kaluli pesquisados por Feld (1982); produzir documentos, no caso da Conferência Mundial das Mulheres etnografada por Riles (2000); ou construir alianças políticas, ou a própria categoria "culturas populares", no caso do Encontro aqui analisado. Como é possível que essas formas modifiquem determinados contextos ou relações sociais? 0 que as pessoas estão fazendo com uma apresentação de um grupo de mestres de carimbó em um encontro como o aqui discutido? Qual a eficácia, os efeitos dessa apresentação? Assim como o choro possuía uma affecting presence entre os kaluli que Feld estudou (1982), essas apresentações artísticas e culturais, vivenciadas enquanto troca de experiências, também são uma presença que afeta as relações que estão sendo construídas e negociadas nessas reuniões. Nos depoimentos dos participantes, ao descrever esse evento, as ideias de "encontro", de "troca de experiências" e de "oportunidade para reconhecer-se" foram muito frequentes, e elas eram associadas tanto às Rodas de conversa e de convivência quanto às apresentações artísticas. Existe uma percepção muito clara de que esse tipo de evento favorece a construção de amizades, parcerias e elos diversos. 
Ao estudar documentos e burocracias, Riles aciona uma sugestiva ideia de Bateson: o tipo de eficácia aqui discutido estaria dado pelo fato de existir "empatia em relação a padrões". No caso das práticas documentais pesquisadas por Riles, isto significa que existem conjuntos definidos de "práticas estéticas" associadas à produção, ao uso e à circulação de determinados tipos de documentos que permitem distingui-los de outros gêneros textuais (RILES, 2006). Esse também parece ser o caso no contexto aqui pesquisado. Os processos que descrevo nos mostram um conjunto de padrões próprios à área cultural e a certo tipo de militância da sociedade civil para os quais a ideia de vivência e de troca de experiências são fundamentais. 0 que se observa é que, a partir do compartilhamento de um conjunto de vivências e de experiências fortemente marcadas por elementos festivos, afetivos e expressivos, entremeadas às discussões políticas, esses representantes da sociedade civil, suas categorias e alianças são "afetados"; são estabelecidas novas relações, e são construídos vocabulários e entendimentos comuns que abrem a possibilidade para a formação de alianças, da própria categoria e de agendas políticas.

\section{Considerações Finais}

Considero que o Encontro é um exemplo dos processos pelos quais a categoria "culturas populares" tem sido construída no cenário dos espaços participativos da área da cultura. Trata-se de um processo que implica em uma relação dinâmica entre, de um lado, categorias e sentidos institucionalizados e, de outro, práticas e performances que atualizam e tensionam estes sentidos. A organização do Encontro pôde, em grande medida, pautar os sentidos que seriam atribuídos às culturas populares ali - isto tanto pela escolha dos colegiados setoriais que participariam do Encontro quanto pela seleção das manifestações que integraram a programação cultural quanto, ainda, pela ambientação e decoração do espaço físico utilizado. Creio ser possível dizer que es- 
ses elementos diversos ecoaram uma imagem de "cultura popular brasileira" bastante recorrente: aquela dos folguedos, de um Brasil negro, índio, mestiço e rural, frequentemente associado ao passado, às origens ou às raízes. Contudo, essa imagem clássica não surge sem tensionamentos. A maneira como os temas de algumas Rodas de Conversa foram construídos, por exemplo, evidenciam uma articulação entre a ideia de "cultura popular" e "tradicional" com temáticas assumidamente contemporâneas e, não raro, urbanas (Como a "Roda Novas tecnologias, juventude e Culturas Tradicionais" ou a "Roda Democratização dos Meios de Comunicação”). Outras Rodas acionaram uma associação entre culturas populares e contextos institucionais (como na "Roda Conhecimentos tradicionais: marcos legais para promoção e proteção"; ou a "Roda Relação do Estado com a sociedade civil”).

A partir da descrição desse Encontro, foi possível perceber também como a construção dessa categoria passa pelo uso de uma linguagem cultural que é, na verdade, pensada como uma maneira específica de se fazer "cultura" - e, também, de se fazer "política". A festa, a dança, o canto, as rezas, frequentemente pensados como alheios à política institucional, não apenas se fazem presentes nos grandes encontros da sociedade civil como, na verdade, são fundamentais na constituição de uma série de elementos reconhecidamente "políticos": a categoria ou segmento a ser representada no espaço institucional; a legitimidade dos representantes; as construções de alianças; a criação de agendas. É importante ainda perceber que, pelo menos no caso do Colegiado Setorial de Culturas Populares, estes elementos festivos, culturais e artísticos se fazem presentes nos espaços institucionais de forma espontânea e inconsciente, mas, também, de maneira consciente, intencional e politicamente agenciada. Existe, na verdade, uma demanda explícita pelo reconhecimento de outras maneiras de fazer política que não a "do governo", e de que as lógicas dos grupos e das práticas culturais representados se façam presentes não apenas nos eventos excepcionais, ou nas margens das reuniões dos colegiados (aberturas, interva- 
los, corredores), mas que possam estar no centro das reuniões e, até, pautá-las. 0 Encontro é justamente exemplo de um evento no qual os defensores dessas proposições tiveram mais espaço para experimentar a construção de uma reunião com "cara" de sociedade civil - ou, no caso específico, de culturas populares.

Contudo, é preciso mencionar que, paralelamente às reservas em relação à maneira do governo fazer política, existe uma valorização de representantes e conselheiros que manejam a "lógica burocrática" dos espaços institucionalizados e governamentais. Frequentemente, é demandado a qualificação ou formação de conselheiros da sociedade civil - o que seria sinônimo de formar conselheiros que conheçam o funcionamento do Estado. Assim também, em grande medida, representantes da sociedade civil "mais experientes" são considerados importantes por saberem como acionar instâncias oficiais e como transitar nos espaços institucionais. Conhecer e saber utilizar o vocabulário específico das reuniões facilita o diálogo e a negociação com os gestores. E, não podemos esquecer, trata-se de fato de um vocabulário específico: assim como no caso das reuniões de associações e sindicatos rurais analisados por Comerford em seu clássico "Fazendo a luta" (1999), reuniões de conselhos, colegiados e conferências também implicam em uma metodologia de trabalho que não é familiar a todos, e cuja particularidade muitas vezes é apontada como causa de exclusão. Assim, distinguir os diferentes tipos de intervenção possíveis, por exemplo, uma questão de ordem de uma questão de esclarecimento, ou ainda de um encaminhamento; saber diferenciar uma resolução de uma moção; saber justificar suas demandas a partir de marcos legais já existentes; tudo isto são habilidades valorizadas em representantes da sociedade civil. Há, portanto, uma tensão interessante entre o que é tido como uma "maneira do governo fazer política" (que é associada a lógicas e processos "burocráticos") e formas de fazer política tidas como próprias à sociedade civil. Ao mesmo tempo em que há uma insistência em distinguir estes polos (Estado e sociedade; cultura e política), há também um esforço por aproximá-los. 
Sem a pretensão de ser conclusivo, este trabalho tem por ambição contribuir com as reflexões sobre práticas políticas contemporâneas, partindo do pressuposto já consolidado de que o Estado não é um bloco monolítico e de que políticas públicas não se reduzem a políticas estatais, mas avançando na descrição de outros processos e categorias centrais, como é o caso de participação, democracia e cidadania. A etnografia da atuação dos representantes da sociedade civil nas instâncias participativas na área da cultura tem permitido observar uma diversidade de rotinas e práticas de Estado que falam de modos de "fazer política" mais gerais em curso hoje no Brasil. Tem também mostrado que elementos às vezes pensados como contrapostos (tal como o institucional e o não institucional, o formal e o informal, o Estado e a sociedade civil, a política e a cultura) são, na verdade, idealizações sociais - no sentido dado ao termo por Herzfeld (2008) - mutuamente implicadas e simultaneamente produzidas. A noção de "participação", especialmente, parece demandar mais estudos.

Conforme colocado por Fassim, "dar direitos" é hierarquizar (2005). Deve-se, portanto, relativizar afirmações de "democratização", "cidadania" ou "ampliação de direitos", perguntando sobre os valores e as novas hierarquias que eles produzem. Toda política pública possui uma dimensão que é moral (Dias, 2012; Fassim, 2005; Moutinho, 2012) e não pode, portanto, ser universalizada, pois é dada por um conjunto de categorias e valores particulares e específicos. O que acontece com "o popular" quando ele ocupa os espaços institucionais pesquisados? Como, por exemplo, alguém pode se legitimar enquanto representante das culturas populares em um colegiado setorial, haja vista ser este um espaço entendido como "institucional" e "burocrático" e as culturas populares serem entendidas como primordialmente "informais" e, em larga medida, "comunitárias"? Como essas lógicas e modos de ser e fazer distintos são acionados nesses espaços participativos? Uma forma específica de ação política se desenha nesses trânsitos, entre esses diferentes espaços, e ao mesmo tempo em que ela inclui alguns grupos e práticas ela, necessariamente, exclui outros. 


\section{Ref erências}

AMARAL, R. Festa “à brasileira”. São Paulo: e-Books Brasil, 2011. (e-book)

BARBALHO, Alexandre. "Políticas culturais no Brasil: identidade e diversidade sem diferença”. In: RUBIM, Antônio Albino; BARBALHO, Alexandre (orgs.) Políticas culturais no Brasil. Salvador: Edufba, 2007.

BOTELHO, Isaura. Romance de formação: FUNARTE e política cultural, 19761990. Rio de Janeiro: Edições Casa de Rui Barbosa, 2001.

BRASIL. Participação social: Conferências Nacionais 2013-2014. Brasília: Secretaria Nacional de Articulação Social; Secretaria-Geral da Presidência da República, 2013. (material de divulgação)

CAVALCANTI, Maria Laura Viveiros de Castro. Carnaval carioca: dos bastidores ao desfile. Rio de Janeiro: Funarte e Editora da UFRJ, 1995.

CALABRE, Lia. "Políticas culturais no Brasil: balanço \& perspectivas". In: RUBIM, Antônio Albino; BARBALHO, Alexandre (orgs.). Políticas culturais no Brasil. Salvador: Edufba, 2007.

Políticas culturais no Brasil. Rio de Janeiro: FVG, 2009.

Políticas e Conselhos de Cultura no Brasil: 1967-1970. Artigo. Disponível em: http://www.casaruibarbosa.gov.br/interna.php?ID_S=260 Acessado em 15/08/10. 2010.

COHN, Gabriel. “A concepção oficial da política cultural nos anos 70”. In: MICELI, Sérgio (org.). Estado e cultura no Brasil. São Paulo: Difel, 1984.

COMERFORD, J. Cunha. Fazendo a luta: sociabilidade, falas e rituais na construção de organizações camponesas. Rio de Janeiro: Relume Dumará/NUAP, 1999. (Coleção Antropologia da Política, 5)

DIAS, Juliana Braz. Dançando ao som da poesia: gêneros de cultura popular e transformação de categorias sociais. In: TRAJANO FILHO, Wilson (org). Travessias antropológicas: estudos em contextos africanos. Brasília: ABA Publicações, 2012.

FASSIN, D. 2005. Compassion and Repression: The Moral Economy of Immigration Policies in France. Cultural Anthropology, v. 20, n. 3, p. 362-387. 2005.

FELD, Steven. Sound and sentiment: birds, weeping, poetics, and song in Kaluli expression. Philadelphia: University of Pennsylvania Press, 1982.

GOHN, M. G. Conselhos gestores e participação sócio-política. São Paulo: Cortez, 2001. 
GELL, Alfred. Art and agency: an anthropological theory. Oxford: Clarendon Press, 1998.

. "The technology of enchantment and the enchantment of techno-

logy". In: The art of anthropology: essays and diagrams. Oxford; New York: Berg, 2006.

HERZFELD, Michael. Intimidade cultural: poética social do Estado-Nação. Coimbra: Edições 70, 2008.

IPEA. Fatores Críticos de Sucesso na Organização de Conferências Nacionais. Brasília: IPEA; Secretaria-Geral da Presidência da República, 2012. [nota técnica]

LEACH, E. Sistemas Políticos da Alta Birmânia. São Paulo: Edusp, 1995 [1954].

MICELI, Sérgio. “O processo de 'construção institucional' na área cultural federal (anos 70)”. In: MICELI, Sérgio (org.). Estado e cultura no Brasil. São Paulo: Difel, 1984.

MINC. Diretrizes Gerais para o Plano Nacional de Cultura. MinC: Brasília: 2007.

As metas do Plano Nacional de Cultura. MinC: Brasília, 2012.

MOUTINHO, Laura. Sobre danos, dores e reparações: The Moral Regeneration Movement - controvérsias morais e tensões religiosas na ordem democrática sul-africana. In: TRAJANO FILHO, Wilson (org). Travessias antropológicas: estudos em contextos africanos. Brasília: ABA Publicações, 2012.

MUNIAGURRIA, 2013. Espaços participativos no Ministério da Cultura brasileiro: crises e disputas na construção de políticas públicas para a cultura. 2013. X Reunião de Antropologia do Mercosul: Situar, actuar e imaginar antropologías desde el Cono Sur. Córdoba - Argentina.

PALMEIRA, Moacir. "Política e tempo: nota exploratória". IN: PEIRANO, Mariza (org.). $\mathrm{O}$ dito e o feito. Ensaio de antropologia dos rituais. Rio de Janeiro: Relume Dumará, 2001.

PEIRANO, Mariza (org.). 0 dito e o feito: ensaios de antropologia dos rituais. Rio de Janeiro: Relume Dumará, 2001.

PEREZ, L. Festa para além da festa. In: AMARAL, L. et al. Festa como perspectiva em perspectiva. Rio de Janeiro: Garamond, 2012.

RILES, Annelise. The network inside out. Ann Arbor: University of Michigan Press, 2000. 
Introduction: In response. In: RILES, Annelise (org). Documents: artifact of modern knowledge. Ann Arbor: University of Michigan Press, 2006a.

RUBIM, Antonio. Políticas culturais entre o possível e o impossível. Texto apresentado no II Encontro de Estudos Multidisciplinares em Cultura. Salvador: 2006.

.Políticas culturais no Brasil: tristes tradições, enormes desafios". In: RUBIM, Antônio; BARBALHO, Alexandre (orgs.) Políticas culturais no Brasil. Salvador: Edufba, 2007.

."Conselhos de cultura” In: Rubim, A; Fernandes, T.; Rubim, I. (orgs.). Políticas culturais, democracia e conselhos de cultura. UFBA: Salvador, 2010. TAMBIAH, Stanley. Leveling crowds: ethnonationalist conflicts and collective violence in South Asia. Berkeley: University of California Press, 1996.

TATAGIBA, Luciana. “Os conselhos e a construção da democracia no Brasil”. In: Rubim, A; Fernandes, T.; Rubim, I. (orgs.). Políticas culturais, democracia e conselhos de cultura. UFBA: Salvador, 2010.

TURNER, V. 0 Processo Ritual: estrutura e anti-estrutura. Petrópolis: Vozes, 1974 [1969].

VIANNA, Catarina. Os enleios da tarrafa: etnografia de uma relação transnacional entre ONGs. São Carlos: EdUFSCAR, 2004. (Coleção Aracy Lopes da Silva/Estudos em Antropologia Social).

Recebido em 15/12/2015

Aprovado em 30/12/2015 
II Parte 
